\title{
Terahertz Spectroscopy in Bio systems and Biomedical Applications
}

\author{
Amit Kumar Bhunia* \\ ${ }^{1}$ Department of physics and Technophysics, Vidyasagar University, India \\ ${ }^{2}$ Department of Physics, Government General Degree College at Gopiballavpur-II, India
}

Submission: August 30, 2017; Published: October 26, 2017

*Corresponding author: Amit Kumar Bhunia, Department of Physics \& Technophysics, Vidyasagar University, Paschim Medinipur \& Department of Physics, Government General Degree College at Gopiballavpur-II, Beliaberh, Paschim Medinipur-721517, India, Email: amitphysics87@gmail.com

\begin{abstract}
The terahertz radiation has very low photon energy and it does not create any ionization hazard for biological systems. It is strongly attenuated by water and very sensitive to water content. Unique absorption spectra due to intermolecular vibrations in this region have been found in different biological materials. Terahertz (THz) spectroscopy provides a powerful tool for characterization of a great many bio molecules and tissues. The unique features of THz make terahertz imaging very attractive for medical applications over the existing imaging techniques. The interest in terahertz imaging and spectroscopy of biologically related applications increasing more and more within the last few years. This paper provides a short review of terahertz spectroscopy in bio systems and recent advances in terahertz spectroscopy techniques in biomedical applications.
\end{abstract}

\section{Mini Review}

Terahertz (THz) radiation (also called T-Rays) is electromagnetic waves between microwaves and the infrared optical band. Its frequency range lies within the range of 0.1 to $20 \mathrm{THz}$ [1]. $1 \mathrm{THz}$ is equivalent to $33.3 \mathrm{~cm}^{-1}$ (wave numbers), or $0.004 \mathrm{eV}$ photon energy, or $300 \mu \mathrm{m}$ wavelength.

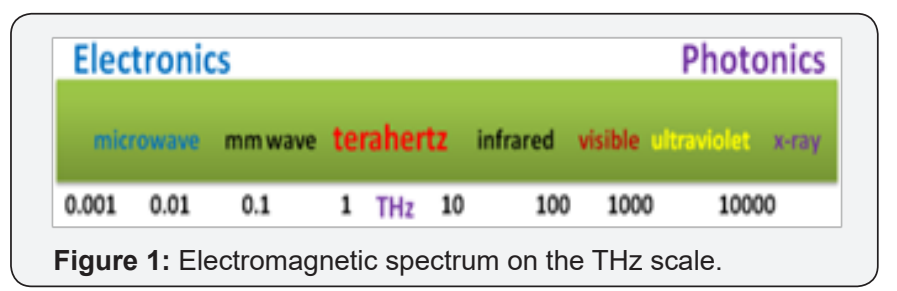

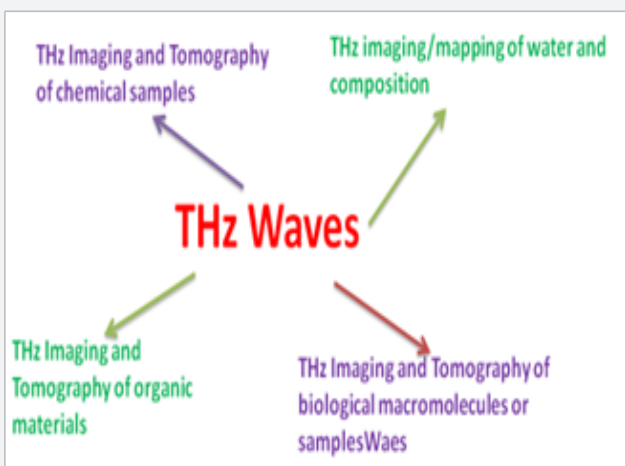

Figure 2: Areas of applications for $\mathrm{THz}$ imaging and tomography.
Terahertz spectroscopy is a powerful tool for characterizing vibrational modes [1] and can probe physical phenomena such as low-energy excitations and carrier dynamics in electronic materials, collective vibrational or torsional modes in condensedphase media, and rotational and vibrational transitions in molecules [2,3]. Terahertz spectroscopy can directly assess the electric field amplitude (Figure 1). Therefore, the amplitude and phase of the post-sample analyzed signal can be obtained directly and simultaneously using a Fourier transforms $[4,5]$. As a result, terahertz radiation now has widespread potential applications in communications, materials, chemistry, Biosensors, Terahertz Imaging, Tissue Spectroscopy, pharmaceutical, and many other fields (Figure 2). The technology on $\mathrm{THz}$ time domain spectroscopy based on laser sources has been promoted as one of the disruptive technologies changing the world [6,7]. THz radiation can penetrate up to several millimetres inside the thin layers of non-metallic substances like plastic, ceramics, and clothing.

Now a day's X-ray is important tools in radiographic imaging technology. Due to ionizing properties of X-ray radiation, it causes some bad effects to our health [8-10]. On the other hand, Terahertz waves are non-ionizing and therefore they do not pose a risk to living organisms. They provide images that are comparable to backscatter X-rays. Although THz has lower resolution than X-Ray, but in many fields of application, it is a more preferable technique [11]. Terahertz technology also 
produces faster results than X-ray and enables non destructive, internal, chemical analysis of materials with applications in a number of industries. The advanced drug delivery techniques with sophisticated surface coatings, any matrix structures, require complex processes for the production of such structures to ensure the quality of the resulting product.

The most common and convenient form of administering drug to a patient is tablet. The most important factors during the manufacturing process are the microstructure, distribution, particle size and morphology of the drug molecules. These factors should properly maintain in a tablet. As THz spectroscopy give rise non-destructive imaging technology, pharmaceutical industry uses it to assess the microstructure of the tablet throughout product development and manufacturing in order to ensure its quality while optimizing the productivity. The $\mathrm{THz}$ spectroscope can ensure the quality by inspecting chemical as well as morphological composition. As compared to other competitive methods like Infrared, FTIR, Raman and X-ray tomography, the $\mathrm{THz}$ technology is capable of mapping and analyzing the internal structures within complex pharmaceutical products non destructively to reveal structural defects. $\mathrm{THz}$ technology can be used for semiconductor inspection, food inspection, pharmaceutical inspection, and 2D and 3D imaging, including medical diagnosis in the areas of skin cancer, THz-3DCT images, tooth structure and tumours [9-11].

$\mathrm{THz}$ reflection pulse imaging was used to study human skin in vivo. Pickwell [12] used broadband THz pulsed imaging system of frequencies approximately $0.5-2.5 \mathrm{THz}$ for investigated freshly excised human tissues. THz imaging was used for oral cancer diagnosis [13]. Wittlin [14] studied the temperature (from 5-300K) dependent properties of highly oriented films of DNA salts, Li-DNA and Na-DNA in the THz region $(0.090-$ $13.5 \mathrm{THz}$ ). They identified five vibrational modes including the lowest frequency modes at $1.35 \mathrm{THz}$ for Li-DNA and $1.23 \mathrm{THz}$ for Na-DNA. They suggested that a simple lattice dynamical model was reasonably successful in explaining the presence of vibrational modes and the impact of hydration on these modes. The Markelz group [15] investigate THz response of several proteins using THz-TDS including hen egg white lysozyme, horse heart myoglobin and bacteriorhodopsin. For Lysozyme and myoglobin powder, broadband absorption without identifiable peaks was observed to increase from $5-40 \mathrm{~cm}-1$ and then leveled off near $80 \mathrm{~cm}-1$.

Upadhya [16] demonstrated the use of terahertz timedomain spectroscopy for measuring absorption spectra in Dand L-glucose, sucrose, uric acid and Allenton. They suggest that the intermolecular vibrational modes may contribute in the $\mathrm{THz}$ frequency range in the molecular spectra of these molecules. Fitzgeret [17] studied the information about the optical properties of human tissue, using a broadband terahertz pulsed imaging system comprising frequencies approximately 0.5 to $2.5 \mathrm{THz}$. They calculate the refractive index and linear absorption coefficient of skin, Adipose tissues, Striated muscle, Vein, Nerve. They observed the higher value of refractive index for De-ionised water $(2.04 \pm 0.07)$ than any tissue in the $\mathrm{THz}$ region. The linear absorption coefficient of muscle is higher than adipose tissue. The higher value of linear absorption for muscle is expected from the higher hydration of muscle. As these samples came from that in vivo clinical a single subject, there is currently insufficient statistical power to draw firm conclusions, but results suggest imaging will be feasible in certain applications [18-21].

The performance of any THz imager depends on two factors:

A. The THz source power and the corresponding detector responsively and sensitivity,

B. The system losses, including component and material absorptions, dispersion and scattering.

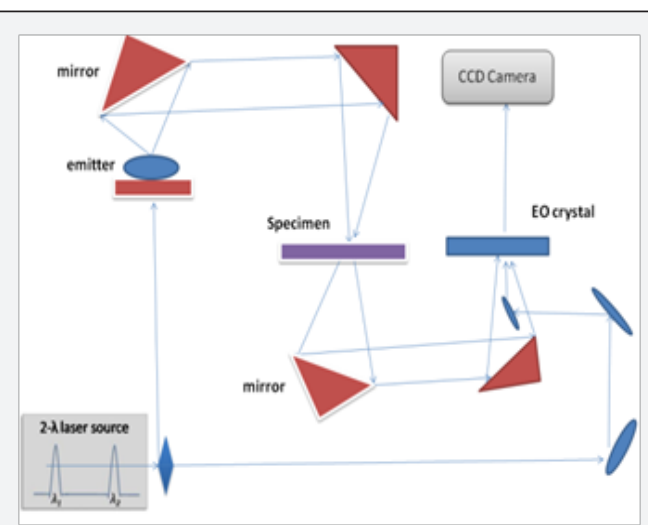

Figure 3: Block diagram of the 2D THz imaging system [21].

Therefore, the suitability of a particular imaging technique to be employed towards a specific application is dependent on the optimized design of the imaging arrangement based on the abovementioned parameters. The difference frequency generation (DFG) is an important technique for THz generation. This technique is suitable for deployment in a $2 \mathrm{D} \mathrm{THz}$ imaging system because it has the potential for narrow line width and wide tuning range (Figure 3).

$\mathrm{THz}$ imaging has the potential to be used in assessing several structures. The development of techniques which utilize terahertz waves for applications in medicine is growing rapidly with the development of instrumentation. Future studies will focus on increasing the resolution of the sampled area and imaging human structures upon reflection in 3-D.

Bakopoulos et al. [18] demonstrate recent advances toward the development of a novel 2D $\mathrm{THz}$ imaging system for brain imaging applications both at the macroscopic and at the bimolecular level. Ouchi [19] developed a high efficient terahertz sources and detectors for $\mathrm{THz}$ imaging and other medical applications. They used a ridge waveguide with $5-7 \mu \mathrm{m}$ width and LiNbO3 based nonlinear terahertz generator. They demonstrated three dimensional imaging of biological tissues. Their observation included differences in physical properties between tumor tissues and normal tissues. 
Ji [20] designed and fabricated a novel terahertz (THz) otoscope. They suggest that their otoscope can help physicians to diagnose otitis media (OM) with both $\mathrm{THz}$ diagnostics and conventional optical diagnostics. Recentlty $\mathrm{THz}$ bio-sensing micro chip for detecting illicit drugs has been developed Hernandez-Cardoso [21] proposes that terahertz reflection imaging method is an important tool for the detection of diabetic foot syndrome in its early stages.

\section{References}

1. Haddad JE, Bousquet B, Canioni L, Mounaix P (2013) Review in terahertz spectral analysis. Trends Anal Chem 44: 98-105.

2. Wang C, Gong J, Xing Q, Li Y, Liu F, et al. (2010) Application of terahertz time-domain spectroscopy in intracellular metabolite detection. J Biophotonics 3(10-11): 641-645.

3. Baxter JB, Guglietta GW (2011) Terahertz spectroscopy. Anal Chem 83: 4342-4368.

4. Pli'nski EF, Plin'nska S (2012) Sensing with terahertz radiation of pharma-and biomaterials. Procedia Eng 47: 929-932.

5. Zhang XC, Xu J (2010) Introduction to THz Wave Photonics. Springer: New York, USA.

6. Smitt PR (1988) Subpico second photo conducting dipole antennas. IEEE J Quantum Electron 24(2): 255

7. Prescouter (2015) 9 Disruptive Technologies Changing the World. Evanston, IL, USA

8. Jason B, Baxter, Glenn W (2011) Terahertz Spectroscopy. Anal Chem 83: 4342-4368.

9. Yookyeong CS, Inhee M, Joo-Hiuk S (2009) Frequency-dependent characteristics of terahertz radiation on the enamel and dentin of human tooth. Curr Appl Phys 9(5): 946-949.

10. Lancaster P, Carmichael F, Britton J, Craddock H, BrettleD, et al. (2013)
Surfing the spectrum- what is on the horizon? Br Dent J 215(8): 401409.

11. Abraham E (2012) Three-dimensional terahertz computed tomography of human bones. Appl Opt 51(28): 6738.

12. Pickwell E, Wallace V P (2006) Biomedical applications of terahertz technology. J Phys D Appl Phys 39(17): R301-R310.

13. Sim YC, Park JY, Ahn KM, Park C, Son JH (2013) Terahertz imaging of excised oral cancer at frozen temperature. Biomed Opt Express 4(8): 1413-1421.

14. Wittlin A, Genzel L, Kremer F, Haseler S, Poglitsch A. Phys Rev A198.

15. Markelz A, Whitmire S, Hillebrecht J, Birge R (2002) Phys Med Biol 47: 3797.

16. Upadhya PC, Shen YC, Davies AG, Linfield EH (2003) Terahertz timedomain spectroscopy of glucose and uric acid. Journal of Biological Physics 29(2-3): 117-121.

17. Fitzgerald AJ, Berry E, Zinov'ev NN, Homer-Vanniasinkam S, Miles RE, et al. (2003) Catalogue of human tissue optical properties at terahertz frequencies. Journal of Biological Physics 29(2-3): 123-128.

18. Bakopoulos P, Karanasiou I, Pleros N, Zakynthinos P, Uzunoglu N, et al. (2009) (CW) and short-pulse optical source for THz brain imaging applications. Meas Sci Technol 20(10): 104001.

19. Ouchi T, Kajiki K, Koizumi T, Itsuji T, Koyama Y, et al. (2014) Terahertz imaging system for medical applications and related high efficiency terahertz devices. J Infrared Milli Terahz Waves 35(1): 118-130.

20. Ji YB, Moon IS, Bark HS, Kim SH, Park DW, et al. (2016) Terahertz otoscope and potential for diagnosing otitis media. Biomedical Optics Express 7(4): 1201-1209.

21. Hernandez-Cardoso GG, Rojas-Landeros SC, Alfaro-Gomez M, Hernandez-Serrano AI, Salas-Gutierrez I, et al. (2016) Terahertz imaging for early screening of diabetic foot syndrome: A proof of concept. Scientific Reports 7: 42124.

\section{Your next submission with Juniper Publishers} will reach you the below assets

- Quality Editorial service

- Swift Peer Review

- Reprints availability

- E-prints Service

- Manuscript Podcast for convenient understanding

- Global attainment for your research

- Manuscript accessibility in different formats

(Pdf, E-pub, Full Text, Audio)

- Unceasing customer service

Track the below URL for one-step submission https://juniperpublishers.com/online-submission.php 